\title{
NC Tool Path and Its Influence on Cutting Force in Peripheral Milling Analyses
}

\author{
Aleksandra Petrović ${ }^{*}$, Slobodan Ivanović ${ }^{2}$, Ljubomir Lukić ${ }^{1}$ \\ ${ }^{1}$ Faculty of Mechanical and Civil Engineering in Kraljevo, University of Kragujevac, Kraljevo (Republic of Serbia) \\ ${ }^{2}$ High technical mechanical school Trstenik (Republic of Serbia)
}

Peripheral pocket or contour milling using flat end milling tool can be performed using different tool paths. This paper presents analysis of possible tool paths and determination of cutting parameters which are dependable of chosen tool path and variable along the tool path. Engagement angle is identified as key parameter dependable of tool path which variations during the process causes the variations of cutting force. Knowledge of changes in engagement angle along the tool path is necessary for simulation and monitoring the cutting force during the machining process.

Special characteristics of tool paths for high speed milling (HSM) and new demands in tool path construction arising with development of HSM machining are presented in this paper.

Simulation of cutting parameters and cutting force variation along the tool path, presented in this paper, can be used as bases for development of methodology for choosing the most adequate tool path for machining of given contour considering minimum cutting force and minimum cutting force variation.

Keywords: Tool path, peripheral milling, cutting force

\section{INTRODUCTION}

Most of mechanical parts consist of faces parallel or normal to a single plane and free form objects require a $2.5 \mathrm{D}$ rough milling operation of the raw work piece, making 2.5 D pocketing one of the most important milling operations. In practice, classical methods of machining in one direction, in both directions and contour parallel milling are still commonly used. Recently, CAM programs developed applications that support HSM machining in terms of application spiral, trochoidal and D tool paths in order to meet high speed machining demands. Using CAM programs for creating tool path, technology designers faces some choices which determine the final shape of tool path. They use their experience knowledge and intuition to choose some of offered options, so that generated tool path still largely depend of individual judgement. Figure 1. shows an example of diferent tool paths generated with the same CAM program for pocket machining.

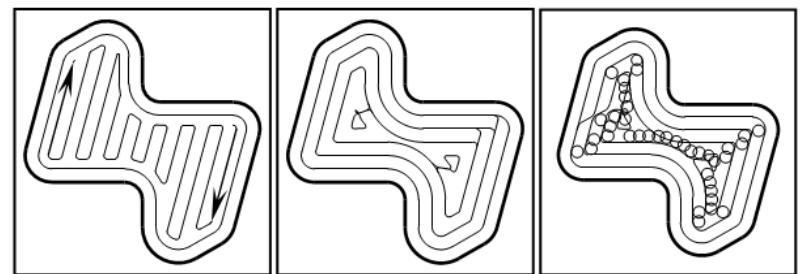

Figue1. Examples of typical tool paths generated by CAM program

Tool path is generaly generated based on the shape of contour (pocket or island), tool diametar and given stepover so that the workpiece is completly machined. It is usually generated by contour offsetting inward or outward. Tool path determines cutting directions, path curvature, changes in cutting directions and nominal values of axial and radial cutting depth.
Actual radial cutting depth changes along the tool path during cutting direction changes, especially at sharp corners. Engagement angle variations are similar to radial cutting depth, except it depends on shape of machining surface: linear, concave or convex). Tool path shape determines it total length, too. Axial depth of cut can be changed by tool path when workpiece isn't prismatic or have some holes.

At each change of direction, the velocity has to be lowered to allow for the smooth change of the motion direction of the tool. How much lower, that depends on the angle between the two successive path segments.

Accordingly, tool path determines axial and radial depth of cut, engagement angle, feed and feed rate profile. Knowledge of the above machining elements along the tool path gives us insight into the adequacy of the generated tool path tools from different aspects. Axial depth of cut, engagement angle and feed rate influence directly on the cutting force value. The suitability of selected tool path for machining can be confirmed experimentally by measuring the cutting force during the milling. In this work, a module developed for simulation and monitoring of machining parameters along the tool path which contribute to cutting force is presented.

\section{NC TOOL PATHS}

Most of mechanical parts consist of faces parallel or normal to a single plane and free form objects require a $2.5 \mathrm{D}$ rough milling operation of the raw work piece, making $2.5 \mathrm{D}$ pocketing one of the most important milling operations. Almost $80 \%$ of the milling operations to produce mechanical parts are produced by NC pocket milling [1].

In usual pocket milling using flat end milling tool, the pocket is generated by sweeping a cylindrical tool inside the pocket boundary. The rotating tool sweeps the 
material to be removed in its feed direction along a set of lines, circles and splines, which are usually referred as tool paths.

NC tool paths can be classified into two major types, namely linear and non-linear. Examples of simple and easy-to-generate linear tool path are the zig and the zig-zag tool paths as shown in Figure 1 (a) and (b). The zig path is a uni-directional cutting path, and hence a consistent up-cut or down-cut chip removal method can be maintained. However, there is a considerable amount of non-productive time involved in returning the cutter to the start-cut position at the end of each cutting path. On the other hand, the zig-zag path is a bi-directional cutting path in which material is removed both in the forward and backward paths. Although the zig-zag tool path can reduce non-productive tool positioning time, it has the disadvantage that the up-cut and down-cut methods are alternately applied. This will lead to problems such as machine chatter and shorter tool life [2].

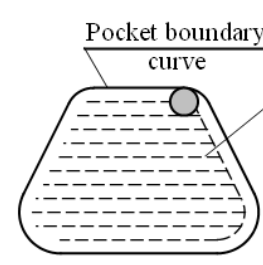

a) $\mathrm{Zig}$ cutter

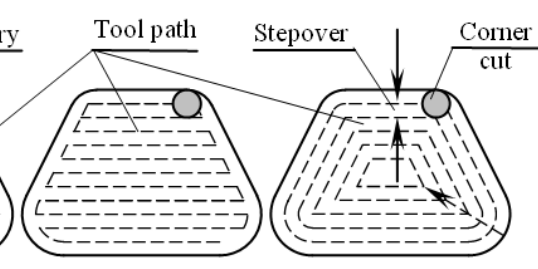

b) Zig zag cutter c) Contour parallel cutter
Figure 2. Three commonly used tool path patterns. (a) Zig cut; (b) zig-zag cut; and (c) contour-parallel cut

As shown in Fig. 1(c), contour-parallel tool path pattern is derived from the boundary of the concerned machining region. It is a coherent tool path in the sense that the cutter is kept in contact with the cutting material most of the time. So it incurs less idle times such as those spent in lifting, positioning and plunging the cutter. At the same time it can also maintain the consistent use of either up-cut or down-cut method throughout the cutting process. Contour-parallel tool path is therefore widely used as a cutting tool path especially for large-scale material removal.

The contour parallel in-out strategy i.e. to cut the material from the middle of the pocket to the outside boundary is usually preferred as it involves first slotting with a minimum length of cut. Spiral in tool paths are usually practiced in automobile and aerospace industry where the thin walled boundaries have high rigidity requirements.
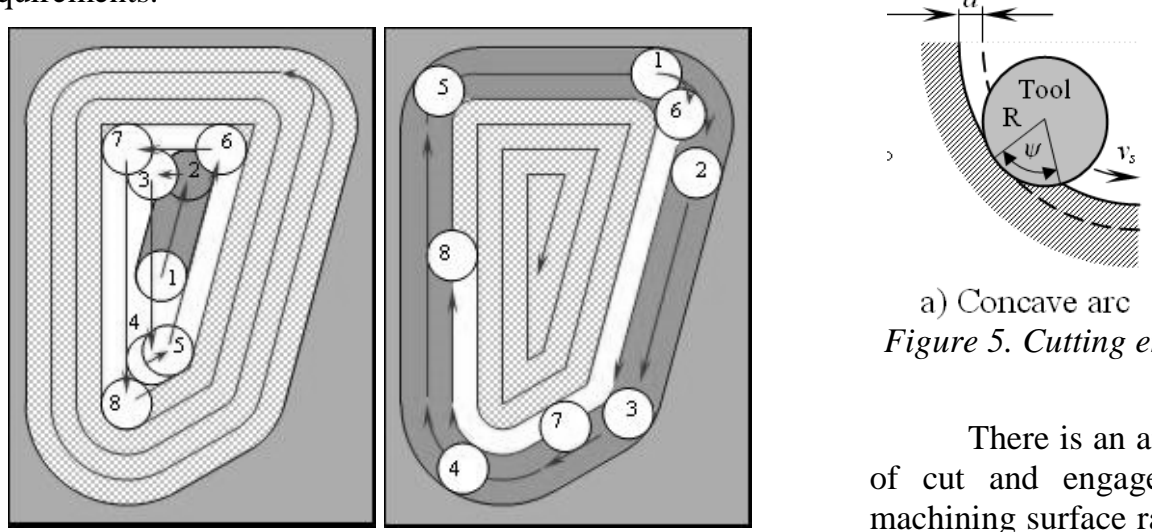

a) Concave arc

\subsection{Engagement zone modelling}

Cutter engagement is a measure that describes what portion of the cutter is actually involved in machining at a given instant of time. During complex milling operations, usually only a portion of cutter engages in cutting and, therefore the cutter engagement varies along the cutter path.

The different engagement conditions during the pocket milling are shown in Figure 4. Engagement angle have different values: $180^{\circ}$ at Figure a), and f), $90^{\circ}$ at Figure b) and d), between $90^{\circ}$ and $180^{\circ}$ at Figure e) and $0^{\circ}$ at Figure c).

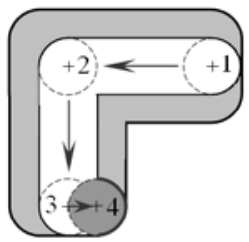

a)

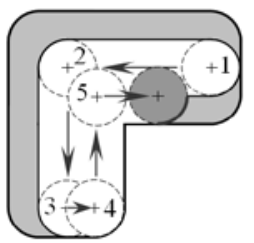

d)

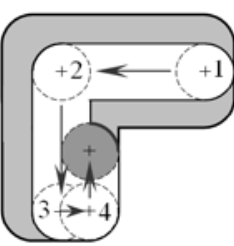

b)

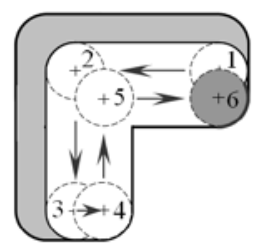

e)

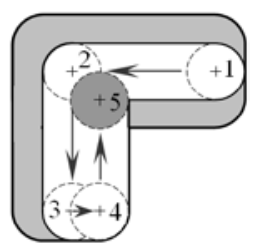

c)

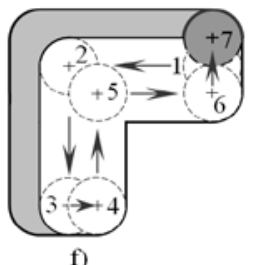

f)
Figure 4. Cutting zone engagement variation in pocket milling

It is clear that as the tool is moving along the tool path the engagement condition can drastically change and hence the cutting loads.

Therefore, by monitoring the cutter engagement, we can monitor and control cutting forces. A sudden increase in cutter engagement may even result in tool breakage. Determination of cutter engagement is essential for adjusting feed rate. Cutter engagement value can also be used in generating efficient cutter paths. Knowledge of radial depth of cut and engagement angle on each segment of the path allows the assessment of the adequacy of the tool path, as well as generating the optimal tool path.

Engagement angle can vary even if the same radial depth of cut is kept. The cutting engagement angle, increases when the tool approaches to a concave corner from linear segment and it decreases when the tool gets to a convex corner from linear segment (Figure 5).

\section{Figure 5. Cutting engagement with constant radial depth of cut}

There is an analytical relation between radial depth of cut and engagement angle including influence of machining surface radius. Values of engagement angle for machining linear, concave and convex surface are given in Table 1. 
Table1: Cutting engagement angles

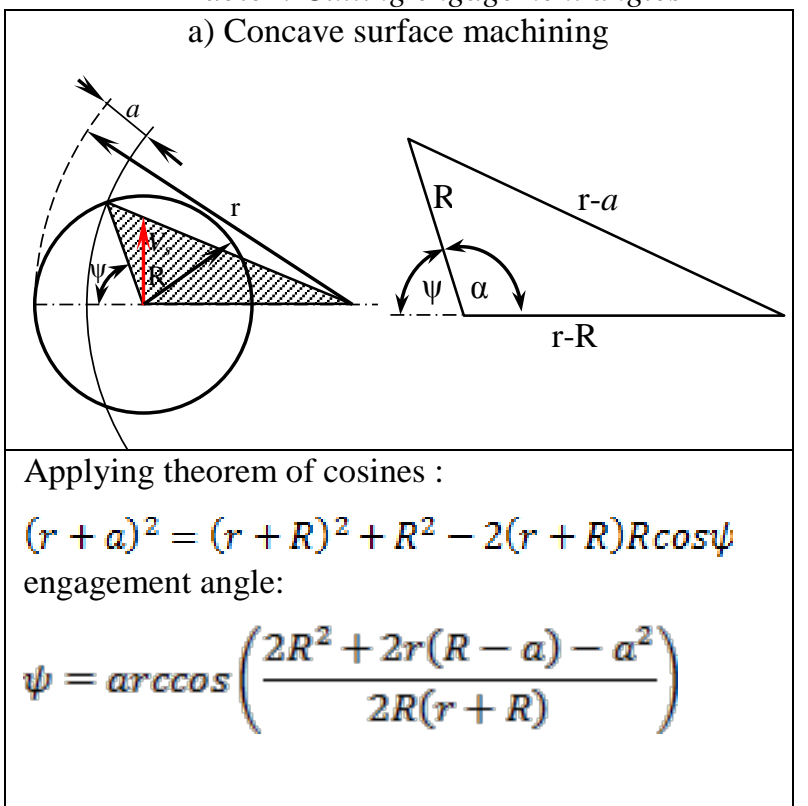

b) Convex surface machining

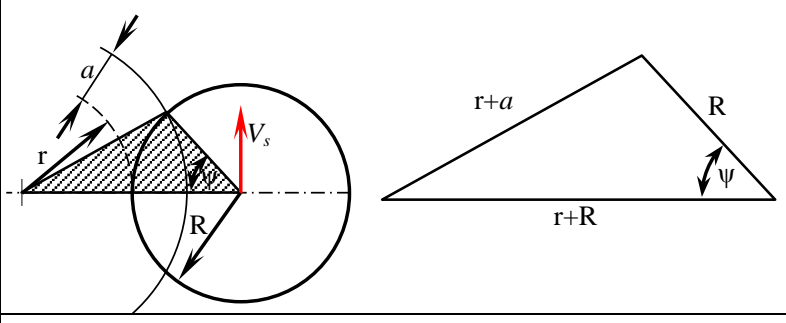

Applying theorem of cosines :

$(r+a)^{2}=(r+R)^{2}+R^{2}-2(r+R) R \cos \psi$

engagement angle:

$\psi=\arccos \left(\frac{2 R^{2}+2 r(R-a)-a^{2}}{2 R(r+R)}\right)$

c) Linear surface machining

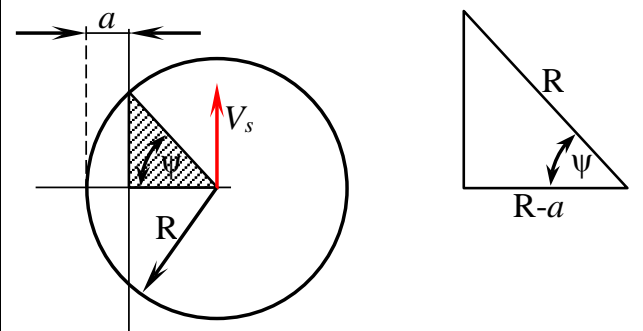

Applying cosines of angle :

$\cos \psi=\frac{R-a}{R}$

engagement angle:

$\psi=\arccos \left(\frac{R-a}{R}\right)$

\section{NC TOOL PATHS FOR HIGH SPEED MILLING OPERATIONS}

After the advent of High Speed Machining (HSM) in aerospace and automotive industries for machining complex machining parts made of aluminium and its alloys, the HSM is becoming increasingly popular as an innovative technology in all the manufacturing sectors. High Speed Milling assures two times more productivity, first in cutting speeds and second in feed rates. Modern High speed machine tools are capable of achieving very high spindle speed up to 50,000 RPM and traverse rates up to $16,000 \mathrm{~mm} / \mathrm{min}$. [3].

In high speed milling (HSM), machining efficiency is improved by increasing cutting speed. For the purpose of lightening cutting resistance, reducing vibration and avoiding distortion, cutting depth is reduced in HSM, so that the operating load is lowered.

The contour-parallel tool path generation is usually purely geometric in nature, which leads to a variation of radial depth of cut especially at sharp corners.

The usual problems encountered due to this variation are: a) left over material at corners b) sudden tool breakage, which leads to choosing worst scenario cutting conditions in manufacturing practices. Also, with the advent of high speed machining, the focus has been to develop smooth and curved tool paths for material removal to ensure machining quality.

From the machine dynamics and cutting tool point of view, the variation in the cutting load affects the tool life as well as the machine tool condition itself. Conventional contour parallel tool path based approaches such as spiral milling although they insure smooth tool paths; they result in a high variation of the radial depth of cut, which influences the tool load and machine dynamics.

Again as per the conventional paths, the problem specially arises at the corners and hence corner cutting or excess material removals at convex corners have long been studied analytically.

For the general cases, there are two popular approaches mentioned in the literature to find the solution for the cutting load variation problem along the machining tool path: feed rate scheduling and tool path strategies. In feed rate scheduling, feed rates are typically programmed for the worst-case scenario to avoid tool breakage. Online optimization routines are sometimes used for maximizing material removal but that require a considerable amount of setup and maintenance efforts for the machine hardware [4].

The type of optimization depends upon the type of cutting tool used, its diameter, length, material, number of flutes and the work piece material. Further, these routines put an extra effort on the machine tool controller as well as the machine components to change feed rate for each block of NC code.

On the other hand, there has been relatively little initiative offered to explicitly modify the tool path itself to avoid the extreme variation of cutting forces in pocketing. The approach to adapt or modify the tool path for achieving a constant load is independent from the cutting tool diameter, length, number of flutes and work piece material. 


\section{CUTTING FORCE MODELLING FOR PHERIPHERAL MILLING}

Cutting forces are modelled related with chip thickness at different ways [5]:

Linear function:

$$
\begin{aligned}
& F_{t j}=b\left(K_{t c} h_{j}(t)+K_{t e}\right) g_{j}\left(\phi_{j}(t)\right), \\
& F_{r j}=b\left(K_{r c} h_{j}(t)+K_{r e}\right) g_{j}\left(\phi_{j}(t)\right)
\end{aligned}
$$

Exponential function:

$$
\begin{aligned}
& F_{t j}=g_{j}\left(\phi_{j}(t)\right) K_{t} b h_{j}(t)^{x_{F}}, \\
& F_{r j}=g_{j}\left(\phi_{j}(t)\right) K_{r} b h_{j}(t)^{x_{F}}
\end{aligned}
$$

Combination of linear and exponential function:

$$
\begin{aligned}
& F_{t j}=b\left(K_{t c} h_{j}(t)^{x_{F}}+K_{t e}\right) g_{j}\left(\phi_{j}(t)\right), \\
& F_{r j}=b\left(K_{r c} h_{j}(t)^{x_{F}}+K_{r e}\right) g_{j}\left(\phi_{j}(t)\right)
\end{aligned}
$$

The angle that tooth $\mathrm{j}$ makes with the normal direction y is described by $\Phi_{j}(\mathrm{t})$ :

$$
\begin{gathered}
\phi_{j}(z)=\phi+j \phi_{p}-\psi \\
\psi=\frac{2 \operatorname{tg} \beta}{D} z
\end{gathered}
$$

The function $g_{j}$ describes whether a tooth is in or out of cut:

$$
g_{j}\left(\phi_{j}(t)\right)=\left\{\begin{array}{cc}
1, & \phi_{s} \leq \phi_{j}(t) \leq \phi_{e} \wedge h_{j}(t)>0, \\
0, & \text { else }
\end{array}\right.
$$

Where, $\Phi_{\mathrm{s}}$ and $\Phi_{\mathrm{e}}$ are the entry and exit angle of the cut.

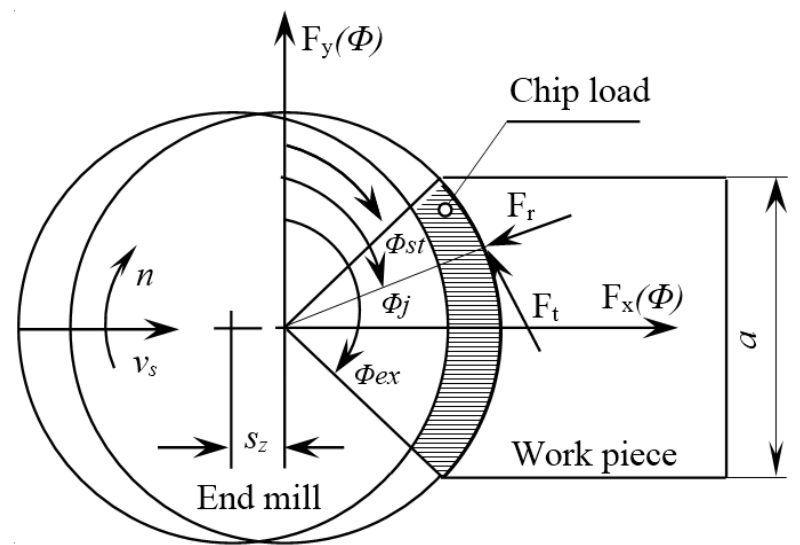

Figure 6: Chip formation phenomenon in milling operation [5]

Herein, the parameters $\mathrm{K}_{\mathrm{tc}}, \mathrm{K}_{\mathrm{rc}}, \mathrm{K}_{\mathrm{te}}$ and $\mathrm{K}_{\mathrm{re}}$ are parameters that can be determined experimentally. The cutting forces are separated as edge (e) and cutting (c) components: an edge force component due to rubbing or ploughing at the cutting edge, represented by $\mathrm{K}_{\text {te }}$ and $\mathrm{K}_{\mathrm{re}}$ on a unit width of cut basis, and a cutting force component due to shearing at the shear zone and friction at the rake face, represented by $K_{\text {tc }}$ and $K_{\text {rc }}$. These parameters are dependent on each material tool combination. However, it is possible to estimate these parameters from orthogonal cutting data, this approach needs orthogonal tests for the orthogonal to oblique cutting transformation.

When the cutting pressure coefficients are identified at low cutting velocities, some phenomena (e.g., material softening, chip segmentation, etc.), which only appear at high cutting speeds, are not considered [6].

For circular tooth path (real tooth path is trochoidal, but effect of the trochoidal tooth path model becomes relevant when considering low immersion levels -when the ratio $a_{\mathrm{e}} / \mathrm{D}$ is small):

$$
h_{j, s t a t}(t)=s_{z} \sin \phi_{j}(t)
$$

With $\mathrm{f}_{\mathrm{z}}$ the chip load in $\mathrm{mm} /$ tooth and $\Phi \mathrm{j}(\mathrm{t})$ the rotation angle of the $j$-th tooth of the tool with respect to the y (normal) axis.

\section{PRAĆENJE PARAMETARA OBRADE I SILE DUŽ PUTANJE GLODANJA}

As can be seen from the preceding analysis, for the efficient controlling of cutting force along the path it is necessary to provide monitoring of cutting parameters along the tool path, primarily the radial depth of cut and cutting engagement angle, as well as monitoring of cutting force itself along the path. The simple examples will demonstrate the system developed to monitor parameters of milling process for such purposes.

First of all, NC code data generated by some of the CAM packages has to be imported the into a database and processed, that for each path segment the coordinates of start and end point, interpolation parameters, cutting conditions and the geometric characteristics of the tool are obtain, which is done according to the methodology given in [8].

Blank is imported in Matlab as a bitmap image representing view of blank from above, where each colour corresponds to an appropriate height of the blank. Figure 7. shows the image of the blank and its appropriate matrix in Matlab, where you can see that a blank don't have to be prismatic, but may not have the horizontal holes.

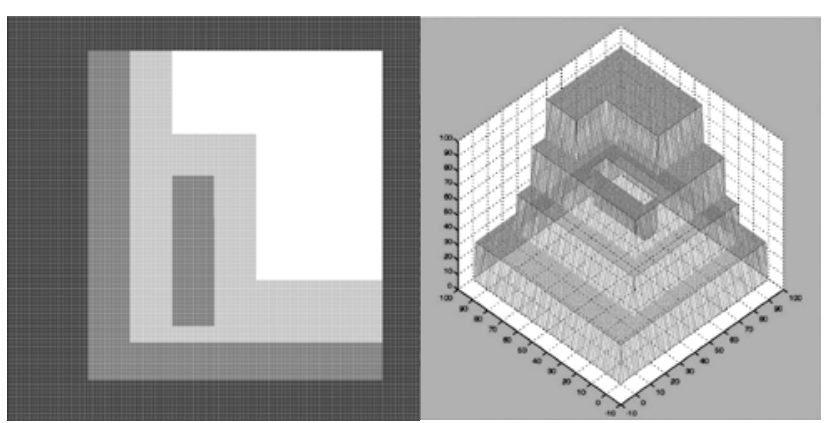

Figure 7. Bitmap image and blank matrix

Then, according to the processed data from the NC program, tool path and the cutter location relative to the workpiece are generated at appropriate spatial intervals along a path as shown in Figure 8.

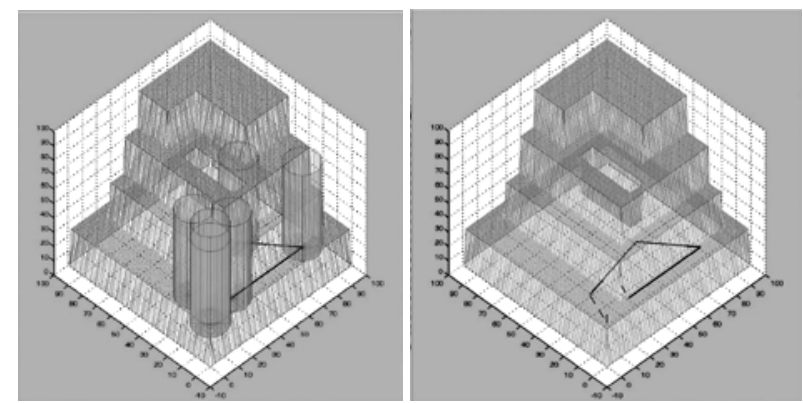

Figure 8. Cutter location relative to workpiece 
Based on the cross-section of the cutting tool volume and the network of the blank, it is determined which section of the volume of the tool is in contact with the blank. In order to determine the angle of engagement and cutting depth in selected points of the tool path it is required to monitor section of the cutter half volume in the direction of the tool velocity in a bottom plane of tool, as well as at the axial depth of cut level (Figure 9). It is also necessary to subtract previously removed material from the blank before computation of these elements.
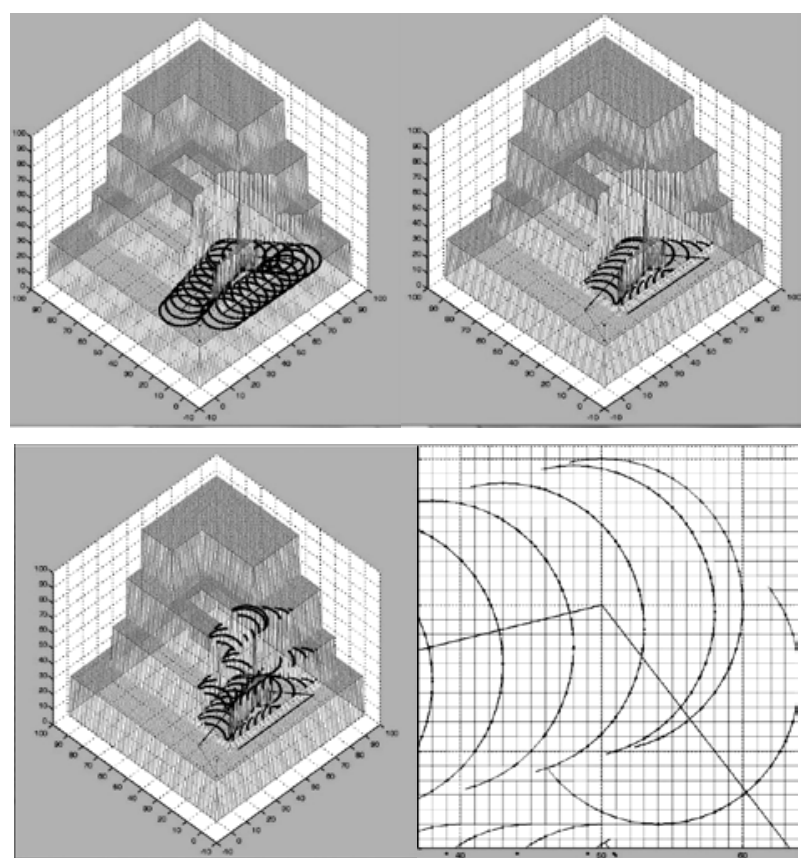

Figure 9. Cross-section of the cutting tool half volume and the network of the blank

Based on cross-section of cutting tool and blank network, values of radial depth of cut and cutting engagement angle are calculated at selected points of the tool path and diagrams of their variation along the tool path are generated (Figures 10, 11 and 12).

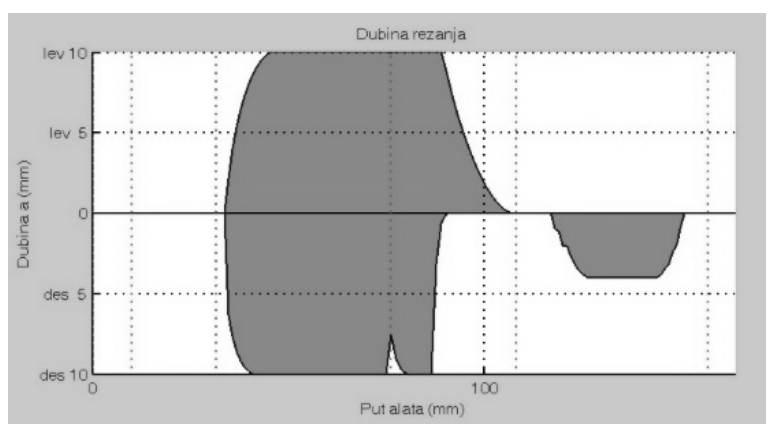

Figure 10. Radial depth of cut along the tool path

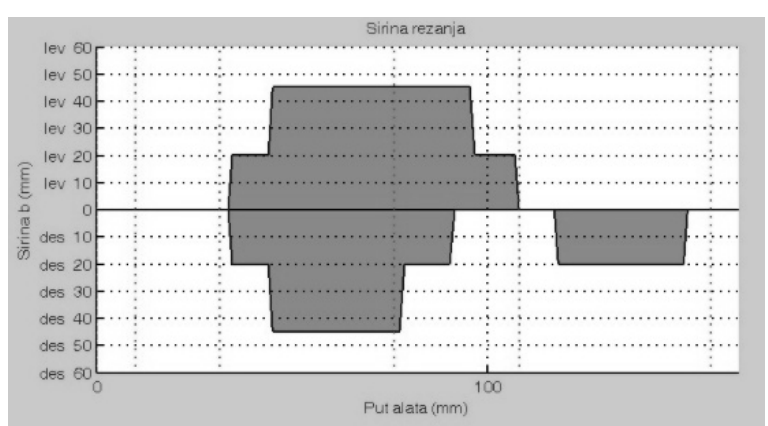

Figure 11. Axial depth of cut along the tool path

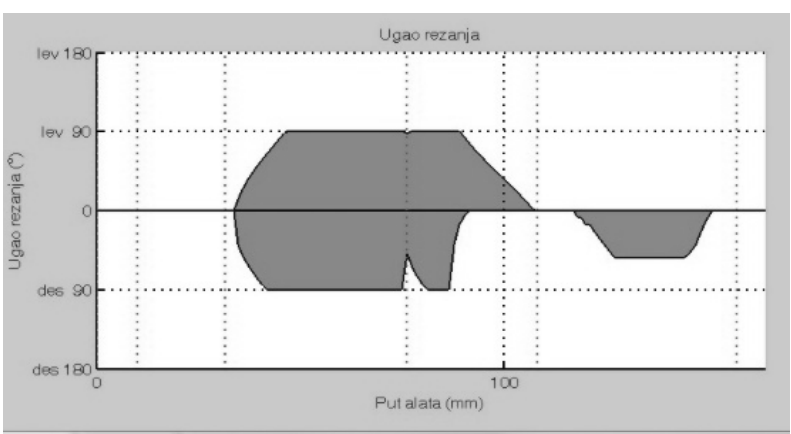

Figure 12. Cutting engagement angle along the tool path

One example of machining with flat end cutter is presented, although a developed program enables the use of tapered and spherical cutters.

On diagrams, values of the elements on the left and right side according to the direction of tool movement are shown separately, so that values that correspond to the up milling and ones that correspond to down milling can be separated.

Applying of the linear model of cutting forces described in Chapter 4 of this paper and engagement angle and axial depth of cut values obtained as shown above, it is possible to determine the value of the cutting force and its change along the tool path.

5.1. An example of monitoring the cutting force along the tool path

Application of the developed program for simulation of machining parameters and cutting forces along the tool path is presented on example of pocket machining on the prismatic blank using complex contour parallel spiral trajectory generated using the EdgeCAM program.

Contouring operation of the inner surface is performed using cutter with $12 \mathrm{~mm}$ diameter, nominal radial cutting depth is $2 \mathrm{~mm}$, for roughing operation cutter with diameter of $20 \mathrm{~mm}$ is used. In Figure 13, pocket contour, tool position on each segment of the tool path and engagement angle values calculated analytically using appropriate formulas from Table 1, are shown. This example is taken from the [9], to check the adequacy of the developed program.

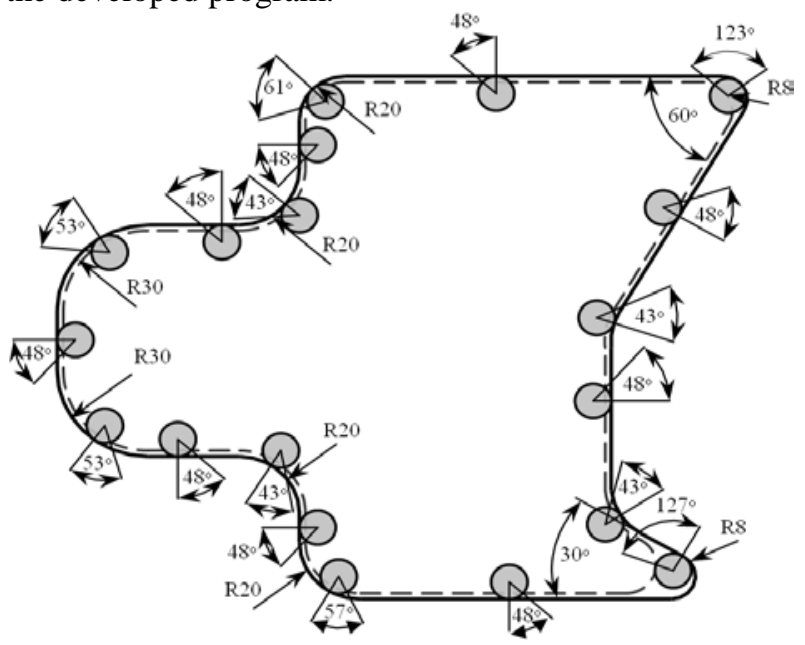

Figure 13. Pocket contouring

Diagram of the engagement angle variation for complete machining of the pocket is shown in Figure 13. Given 
three-dimensional view clearly show the profile of the engagement angle along the projected tool path.

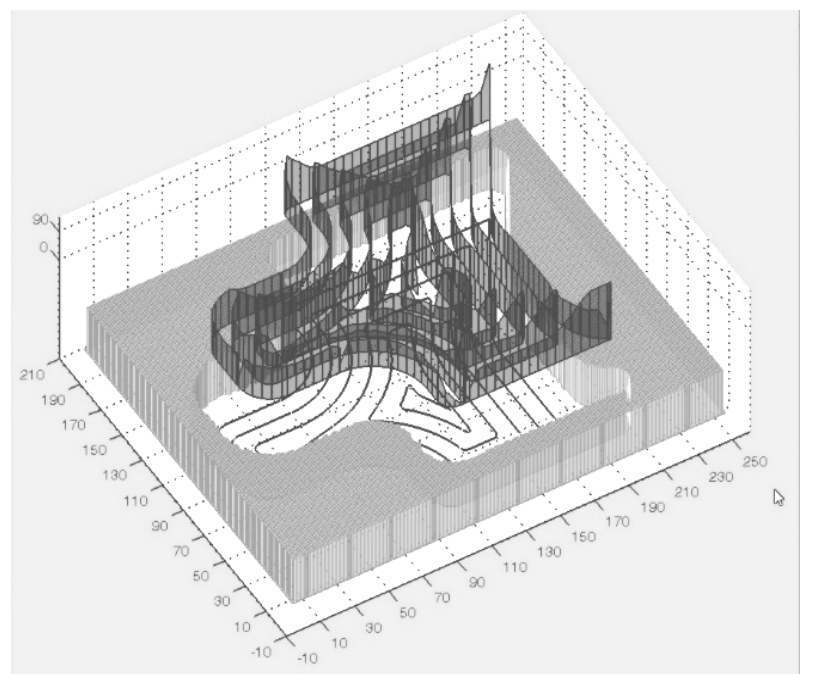

Figure 14. Profile of the engagement angle along the projected tool path

Cutting forces for given example are calculated using cutting force coefficients from Table 2. These are values obtained from experimental slot milling, taken from [10].

Tabela 2: Cutting force coefficients [10]

\begin{tabular}{|l|l|l|}
\hline $\begin{array}{l}\text { Cutting force } \\
\text { coefficient }\end{array}$ & $\begin{array}{l}\text { T01 } \\
\text { Ø6r1f2 }\end{array}$ & $\begin{array}{l}\text { T03 } \\
\text { Ø10r1.5f2 }\end{array}$ \\
\hline Ktc [MPa] & 1090.699 & 661.457 \\
\hline Krc [MPa] & 718.304 & 47.019 \\
\hline Kac [MPa] & 140.915 & 83.538 \\
\hline Kte [N/mm] & 12.855, & 22.835 \\
\hline Kre [N/mm] & 4.787 & 24.492 \\
\hline Kae $[N / m m]$ & 1.620 & 0.858 \\
\hline
\end{tabular}

Resulting cutting force diagram obtained using corresponding values of engagement angle presented at Figure 14 and cutting force coefficients from Table 2 is shown at Figure 15. In order to compare this simulation values with experimental ones diagram is transformed in time domain.

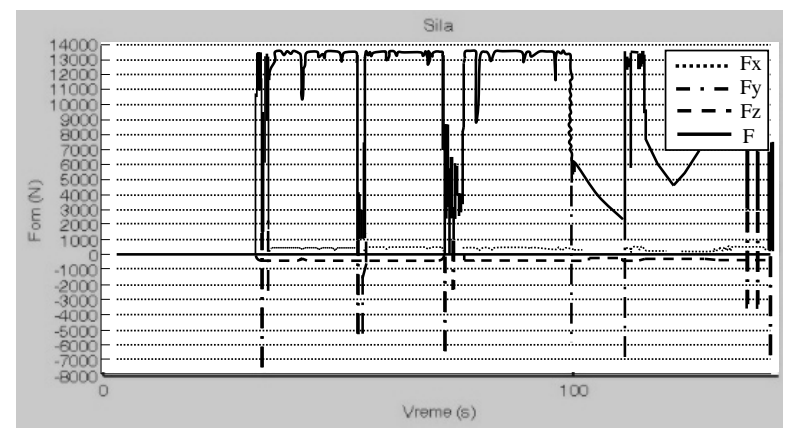

Figure 15. Simulated cutting force during the time

This diagram is compared with simulated cutting force diagram and with measured cutting force diagram presented in [10]. Results seems to be very similar. More accurate adequacy assessment of developed simulation model will be presented in future work.

\section{CONCLUSION}

The program developed to simulate the processing parameters allows you to track changes in depth and width of the cut and engagement angle along the tool path. On the basis of these variations cutting force during the milling process can be monitored. Based on the analysis of the cutting force diagram for the different tool paths, in the future work a methodology for assessing the tool path and selection of the most appropriate path from the point of minimum cutting force variations will be develop. The analysis can also include other criteria such as tool wear, the total processing time and process stability. Also, it is required to include the impact of feed rate variability in points of changing tool velocity direction. This would allow to comprehend all aspects of the cutting process and enable selection of the optimal tool path.

\section{REFERENCES}

[1] Sandeep DHANIK, "NC Tool Path Evaluator and Generator for High Speed Milling,” vol. 4533. ÉCOLE POLYTECHNIQUE FÉDÉRALE DE LAUSANNE, Lausanne, Switzerland, p. 201, 2009.

[2] H. S. Choy and K. W. Chan, “A corner-looping based tool path for pocket milling," Comput. Des., vol. 35, no. 2, pp. 155-166, Feb. 2003.

[3] Z. Y. Zhao, C. Y. Wang, H. M. Zhou, and Z. Qin, "Pocketing toolpath optimization for sharp corners," $J$. Mater. Process. Technol., vol. 192-193, pp. 175-180, 2007.

[4] M. S. UDDIN, S. IBARAKI, A. MATSUBARA, S. NISHIDA, and Y. KAKINO, "Constant Engagement Tool Path Generation to Enhance Machining Accuracy in End Milling,” JSME Int. J. Ser. C, vol. 49, no. 1, pp. 43-49, 2006.

[5] A. Petrović, Lj. Lukić, M. Pljakić, "Machining parameters influence on cutting force used for tool path optimization in end milling”, VIII International Conference "Heavy Machinery -HM2014" Zlatibor, 2528 June 2014, B.19-25

[6] S. Aggarwal, "Part Programming to Realize Chatter Free and Efficient High Speed Milling,” EPFL, Lausanne, Switzerland, 2012.

[7] I. Zaghbani and V. Songmene, “A force-temperature model including a constitutive law for Dry High Speed Milling of aluminium alloys," J. Mater. Process. Technol., vol. 209, no. 5, pp. 2532-2544, Mar. 2009.

[8] S.Ivanović , Lj.Lukić , Z.Petrović: Reconfiguring the database of a flexible production system based on parameters from the NC program, Expert and scientific magazine IMK-14 research and Development, Institute IMK 14.October,Krusevac, yearXIV,no.(28-29) 12/2008,p.79- 84.

[9] Z. Li and S. Zhang, "Cutting Conditions Optimization of Circular Milling Based on Dynamic Modeling and Simulation,” in 2010 International Conference on Measuring Technology and Mechatronics Automation, 2010, vol. 1, pp. 878-881.

[10] N. Nesic, "Modeling and Simulation of Energy Efficient Milling Process Plans for Prismatic Parts,” ÉCOLE POLYTECHNIQUE FÉDÉRALE DE LAUSANNE, 2012. 